\title{
Effect of external energy on atomic, crystalline and powder characteristics of antimony and bismuth powders
}

\author{
VIKRAM V DABHADE* ${ }^{*}$ RAMA MOHAN R TALLAPRAGADA ${ }^{\dagger}$ and \\ MAHENDRA KUMAR TRIVEDI ${ }^{\dagger \dagger}$ \\ Formerly Visiting Scientist, Lehigh University, Bethlehem, PA, USA \\ ${ }^{\dagger}$ Visiting Professor at USC, Los Angeles and OSU, Stillwater, USA, Currently Scientific Advisor, \\ Society for Divine Life \\ ${ }^{\dagger \dagger}$ Founder and President, Society for Divine Life, A4-14, Kanwal Apartment, Four Bungalows, \\ Andheri (West), Mumbai 400 053, India
}

MS received 2 November 2008; revised 7 February 2009

\begin{abstract}
Next to atoms and molecules the powders are the smallest state of matter available in high purities and large quantities. The effect of any external energy on the shape, morphology and structure can thus be studied with relative ease. The present investigation deals with the effect of a non-contact external energy on the powders of antimony and bismuth. The characteristics of powders treated by external energy are compared with the as received powders (control). The average particle sizes, $d_{50}$ and $d_{99}$, the sizes below which $\mathbf{9 9 \%}$ of the particles are present showed significant increase and decrease indicating that the energy had caused deformation and fracture as if the powders have been subjected to high energy milling.

To be able to understand the reasons for these changes the powders are characterized by techniques such as X-ray diffraction (XRD), surface area determination (BET), thermal analytical techniques such as DTA-DTG, DSC-TGA and SDTA and scanning electron microscopy (SEM).

The treated powder samples exhibited remarkable changes in the powder characteristics at all structural levels starting from polycrystalline particles, through single crystal to atoms. The external energy had changed the lattice parameters of the unit cell which in turn changed the crystallite size and density. The lattice parameters are then used to compute the weight and effective nuclear charge of the atom which showed significant variation. It is speculated that the external energy is acting on the nucleus through some reversible weak interaction of larger cross section causing changes in the proton to neutron ratios. Thus the effect is felt by all the atoms, and hence the unit cell, single crystal grain and grain boundaries. The stresses generated in turn may have caused deformation or fracture of the weak interfaces such as the crystallite and grain boundaries.
\end{abstract}

Keywords. Antimony; bismuth; external energy; powder.

\section{Introduction}

Apart from atoms and molecules the next smallest materials available are powders. These could be single crystalline or polycrystalline, the particle size of which is in the micrometric or nano metric range $(<100 \mathrm{~nm}$ ) (Suryanarayana 1995, 1999). Particles exhibit fine microstructures and can contain such a high density of defects (point defects, dislocations, sub (crystallite) boundaries, grain boundaries, inter phase boundaries, etc.) that the spacing between neighbouring defects in nano size powders can even approach the inter atomic distance (Gleiter 1992). As the grain size becomes smaller and smaller, a larger and larger fraction of atoms resides on the single crystal

*Author for correspondence (vvdabhade $@$ gmail.com) grain boundaries (at a $6 \mathrm{~nm}$ grain size, nearly half the atoms reside on the grain boundaries), thus the behaviour of nano sized powders is often dominated by events at the grain boundaries (Mayo 1996).

Due to the extremely small size of the grains and a large fraction of the atoms located at the grain boundaries, materials made from these powders possess properties like higher strength/hardness, enhanced diffusivity, improved ductility/toughness, reduced elastic modulus, increased specific heat, higher electrical resistivity, higher thermal expansion coefficient, lower thermal conductivity, and superior magnetic properties much improved over those exhibited by conventional grain sized $(>10 \mu \mathrm{m})$ polycrystalline materials (Suryanarayana 1995).

Both micro meter and nano meter sized powders are produced by methods like mechanical milling (Mohan et al 1999), inert gas condensation, spray conversion process, 
chemical processes (Amarchand et al 2000), and electro deposition (Suryanarayana 1995), etc. Often mechanical milling is used for synthesis of fine and nano sized powders in bulk quantities using simple equipment and at room temperature (Suryanarayana 1999). During this process, the metal powder particles are subjected to severe mechanical deformation from collisions with the milling tools. Consequently, plastic deformation at high strain rates $\left(\sim 10^{3}-10^{4} \mathrm{~s}^{-1}\right)$ occurs within the particles and the average grain size can be reduced to a few nanometers after extended milling (Benjamin 1976; Fecht 1996). Plastic deformation generally occurs by slip and twinning at low and moderate strain rates, while at high strain rates it occurs by the formation of shear bands, consisting of dense networks of dislocations. The plastic strain in the material increases due to increasing dislocation density in the early stages of ball milling. At a threshold dislocation density, even at moderately elevated temperatures, the material relaxes into sub grains separated by low-angle boundaries, leading to a decrease of atomic level strain. During subsequent milling the process of high deformation/sub grain formation is repeated resulting in the sub grains becoming finer and finer, and the relative orientation of the sub grains with respect to each other ultimately becoming completely random. Once the sub grains reach a critical level of refinement, further refinement becomes virtually impossible since the stresses required for dislocation movement are enormously high due to the Hall-Petch strengthening. Thus nano sized powders with a minimum grain size are produced (Suryanarayana 1999). Titanium powders of about $2 \mu$ particle size when subjected to high energy attrition milling in an argon atmosphere after $15 \mathrm{~h}$ of milling yielded an average particle size of $35 \mathrm{~nm}$ (Dabhade et al 2001). Thus it is now possible to produce large quantities of ultra fine and nano powders by high energy milling.

In the present study the effect of a non contact external energy on antimony and bismuth powders was investigated. These powders were chosen as they belong to the same group in the periodic table and have low melting points. Metals of low melting point generally exhibit low bond energy and were thought to be more significantly affected by the external energy. Powders were chosen as they are the finest form of these metals readily available in high purity levels. Powders also exhibit a high surface area and thus were expected to be more receptive to the external energy.

\section{Experimental}

Antimony and bismuth powders (-325 mesh) of $99.5 \%$ purity were obtained from Alpha Aesar. Five sets of each powder were prepared, the first set which was untreated was designated as control while the other sets exposed to external energy referred to as treated samples. The con- trol and the treated samples were characterized by X-ray diffraction (XRD), laser particle size analysis, surface area determination (BET), differential thermal analysis (DTA-DTG), differential scanning calorimetry (DSC), thermogravimetric analysis (TGA), simultaneous differential thermal analysis (SDTA) and scanning electron microscopy (SEM).

Average particle size and size distribution were obtained using SYMPATEC HELOS-BF laser particle size analyzer with a detection range of $0 \cdot 1-875 \mu \mathrm{m}$ (micro meters). From the particle size distribution, $d_{50}$, the average particle size and $d_{99}$ (maximum particle size below which $99 \%$ of particles are present) for the control (untreated or as received powders) are taken as standard and are compared with the results obtained on four separately treated powders. Surface area determination was carried out on a SMART SORB 90 BET surface area analyser with a measuring range of $0 \cdot 2-1000 \mathrm{~m}^{2} / \mathrm{g}$. X-ray diffraction was carried out using a powder Phillips, Holland PW 1710 XRD system. A copper anode with nickel filter was used. The wavelength of the radiation was $1.54056 \AA\left(10^{-10} \mathrm{~m}\right.$ or $10^{-8} \mathrm{~cm}$ ). The data is obtained in the form of $2 \theta$ vs intensity chart as well as a detailed table containing $2 \theta^{\circ}$, $d$ value $\AA$, peak width $2 \theta^{\circ}$, peak intensity counts, relative intensity \%, etc. The ' $d$ ' values are compared with standard JCPDS data base and the Miller indices $h, k$ and $l$ for various $2 \theta^{\circ}$ values are noted. The data are then analysed using PowderX software to obtain lattice parameters and unit cell volume. Differential thermal (DTA)-thermogravimetric (TGA) combined analyses were carried out from room temperature to $900^{\circ} \mathrm{C}$ at a heating rate of $10^{\circ} \mathrm{C} / \mathrm{min}$ for antimony powders while for bismuth powders it was carried out from room temperature to $400^{\circ} \mathrm{C}$ at a heating rate of $5^{\circ} \mathrm{C} / \mathrm{min}$. Scanning electron microscopy of control and treated powders was carried out using a JEOL JSM-6360 instrument.

The details of the experiments and the original data obtained prior to analysis are given in link: http:// www.divinelife.us/Transcendental_Science/Transcendental_Science.html.

\subsection{Method of data analysis}

The percent change in particle size of various treated powders with respect to control powders were computed using the formula

$$
\begin{aligned}
& \text { Percent change in average particle size }= \\
& \qquad d_{50}(\%)=100 \times\left(d_{50 \mathrm{t}}-d_{50 \mathrm{c}}\right) / d_{50 \mathrm{c}} .
\end{aligned}
$$

In a similar manner the change in particle size of $d_{99}(\%)$ was computed. Percent change in BET surface was calculated in a similar manner as indicated in (1).

The crystallite size was calculated using the formula

Crystallite size $=k \lambda / b \cos \theta$, 
where $\lambda$ is the wavelength of $X$-radiation used $(1.54056 \times$ $\left.10^{-10} \mathrm{~m}\right)$ and $k$ the equipment constant with a value of $0 \cdot 94$. The obtained crystallite size will be in nano meters or $10^{-9} \mathrm{~m}$. Crystallite size in metals can correspond to sub grain size when the grain size is equivalent to single crystal size. It is also possible that some part of the observed X-ray peak width could be due to the instrument broadening (already corrected) while the other part could be due to the strain in the crystal lattice.

The change between various powders is assessed by using relative parameters as follows: Percent change in lattice parameter is the ratio of difference in the values between control and treated samples to the value of control sample expressed as per cent. Typically for the parameter ' $a$ ' this is equal to $100 \times\left(\Delta a / a_{\mathrm{c}}\right)$ where $\Delta a=$ $\left(a_{\mathrm{t}}-a_{\mathrm{c}}\right) / a_{\mathrm{c}}$. This is also known as strain, and, when multiplied with the elastic modulus gives the force applied on the atoms. When the force is compressive the change is negative while a positive value indicates a stretching or tensile force. In a similar manner the percent change in unit cell volume and crystallite sizes are computed.

The weight of atom is computed from the sum of all electrons, protons and neutrons.

Weight of atom $=$ number of protons $\times$ weight of proton + number of neutrons $\times$ weight of neutron + number of electrons $\times$ weight of electron.

Since the number of atoms per unit cell of the crystal is known, the weight of the unit cell is computed. The latter divided by the volume of the unit cell gave the theoretical density. Since the volume of unit cell of the powder changed on treatment, the density as well as weight of atom had also changed.
The weight of the atom when multiplied by the Avogadro's number $\left(6.023 \times 10^{23}\right)$ gave the atomic weight (M) or the weight of a gram atom of the substance. The ratio difference in atomic weight between control and treated samples to the atomic weight of control sample is then expressed as per cent change in atomic weight. Typically this is same as $100 \times\left(\Delta M / M_{\mathrm{c}}\right)$ where $\Delta M=$ $\left(M_{\mathrm{t}}-M_{\mathrm{c}}\right) / M_{\mathrm{c}}$. This value also represents the percent change in sum of weights of protons and neutrons in the nucleus.

The percent change in positive charge per unit volume is computed as follows:

The atomic radius is obtained by dividing the lattice parameter ' $a$ ' with $2, r=a / 2$.

Then the volume of the atom is obtained by assuming it to be spherical, $V=4 \pi r^{3} / 3$.

The positive charge per unit volume of the atom is computed by multiplying the number of protons $(p)$ in the atom with elementary charge $1.6 \times 10^{-19}$ coulombs and then by dividing with the volume of the atom. The percent change in positive charge per unit volume, $\Delta Z$, between control and treated samples is then obtained as

$$
\Delta Z \%=100\left(Z t^{+}-Z c^{+}\right) / Z c^{+} .
$$

\section{Results and discussion}

\subsection{Particle size}

Average particle sizes, $d_{50}$ and $d_{99}$, the particle sizes below which $99 \%$ of the particles are present are shown in tables 1(a)-(b). Antimony powders exhibited a decrease in the

Table 1(a). Particle size of control and treated powder for $d_{50}$.

\begin{tabular}{|c|c|c|c|c|c|}
\hline \multirow[b]{2}{*}{ Treatment } & \multirow{2}{*}{$\begin{array}{c}\text { Average } \\
\text { particle size }\end{array}$} & \multicolumn{2}{|c|}{ Particle size in micrometers } & \multicolumn{2}{|c|}{ Percent change in particle size } \\
\hline & & Antimony & Bismuth & Antimony & Bismuth \\
\hline Control & $d_{50}$ & $34 \cdot 5$ & $31 \cdot 2$ & & \\
\hline$T 1$ & $d_{50}$ & $25 \cdot 7$ & 21 & $-25 \cdot 5$ & $-32 \cdot 7$ \\
\hline$T 2$ & $d_{50}$ & $30 \cdot 7$ & $38 \cdot 3$ & $-11 \cdot 0$ & $22 \cdot 8$ \\
\hline$T 3$ & $d_{50}$ & $25 \cdot 1$ & $32 \cdot 5$ & $-27 \cdot 2$ & $4 \cdot 2$ \\
\hline$T 4$ & $d_{50}$ & $31 \cdot 5$ & $34 \cdot 4$ & -8.7 & $10 \cdot 3$ \\
\hline
\end{tabular}

Table 1(b). Particle size of control and treated powder for $d_{99}$.

\begin{tabular}{|c|c|c|c|c|c|}
\hline \multirow[b]{2}{*}{ Treatment } & \multirow{2}{*}{$\begin{array}{c}\text { Average } \\
\text { particle size }\end{array}$} & \multicolumn{2}{|c|}{ Particle size in micrometers } & \multicolumn{2}{|c|}{ Percent change in particle size } \\
\hline & & Antimony & Bismuth & Antimony & Bismuth \\
\hline Control & $d_{99}$ & $118 \cdot 9$ & $110 \cdot 9$ & & \\
\hline Treated $T 1$ & $d_{99}$ & $87 \cdot 4$ & $66 \cdot 3$ & $-26 \cdot 5$ & $-40 \cdot 2$ \\
\hline Treated $T 2$ & $d_{99}$ & $84 \cdot 3$ & $125 \cdot 1$ & $-29 \cdot 1$ & $12 \cdot 8$ \\
\hline Treated $T 3$ & $d_{99}$ & $89 \cdot 5$ & $111 \cdot 5$ & $-24 \cdot 7$ & $0 \cdot 5$ \\
\hline Treated $T 4$ & $d_{99}$ & $106 \cdot 2$ & $105 \cdot 3$ & $-10 \cdot 7$ & $-5 \cdot 0$ \\
\hline
\end{tabular}




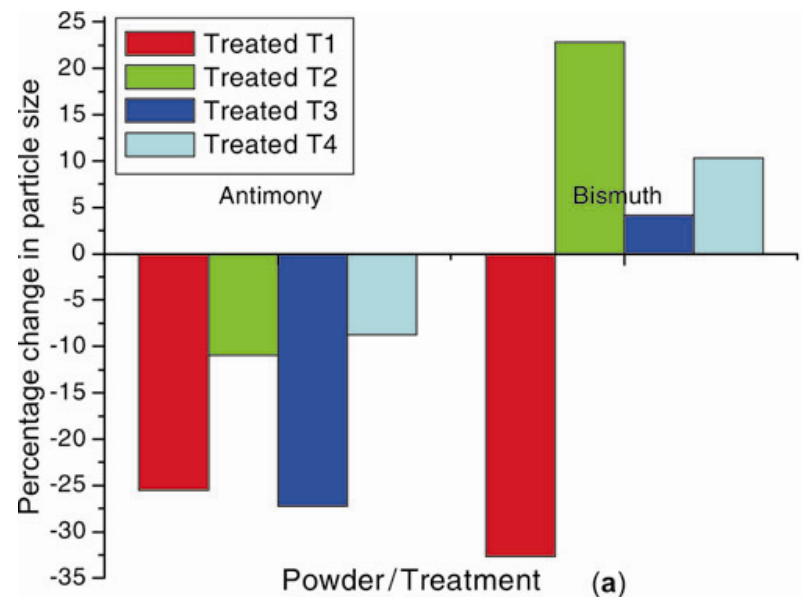

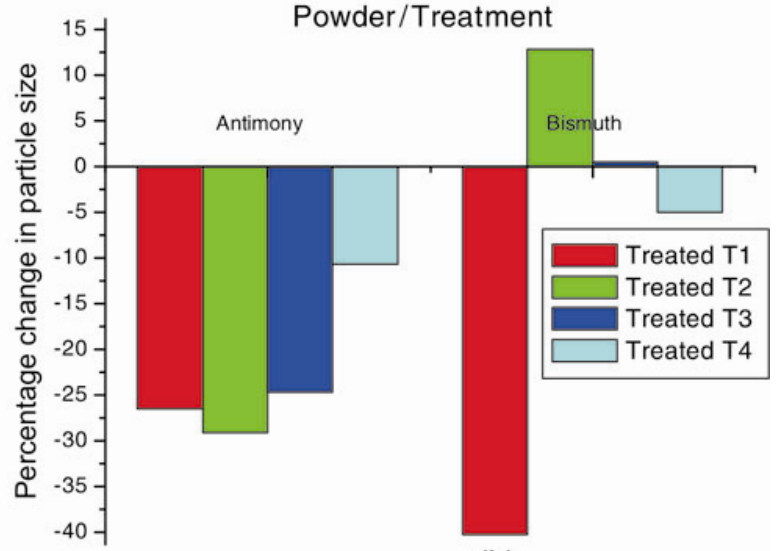

(b)

Figure 1. (a) Percentage change in $d_{50}$ particle size in treated powders and (b) percentage change in $d_{99}$ particle size in treated powders.

Table 2. Physical and mechanical properties of antimony and bismuth.

\begin{tabular}{lcc}
\hline Physical/mechanical property & Antimony & Bismuth \\
\hline Crystal structure & Rhombohedral & Rhombohedral \\
Atomic weight & $121 \cdot 75$ & $208 \cdot 98$ \\
Atomic number & 51 & 83 \\
Number of neutrons & 71 & 126 \\
Effective nuclear charge $5 s$ & $11 \cdot 61$ & $15 \cdot 24$ \\
Effective nuclear charge $5 p$ & $9 \cdot 99$ & $13 \cdot 34$ \\
Density at $25^{\circ} \mathrm{C}(\mathrm{g} / \mathrm{cc})$ & $6 \cdot 697$ & $9 \cdot 808$ \\
Melting point $\left({ }^{\circ} \mathrm{C}\right)$ & $630 \cdot 7$ & $271 \cdot 4$ \\
Boiling point $\left({ }^{\circ} \mathrm{C}\right)$ & 1587 & 1564 \\
Latent heat of fusion $(\mathrm{J} / \mathrm{g})$ & $163 \cdot 17$ & $52 \cdot 976$ \\
Latent heat of vaporization $(\mathrm{J} / \mathrm{g})$ & 1602 & $854 \cdot 78$ \\
Coefficient of linear thermal & $8-11$ & $13 \cdot 2$ \\
expansion at $20^{\circ} \mathrm{C}(\mu \mathrm{m} / \mathrm{m} . \mathrm{k})$ & & \\
Specific heat $(\mathrm{J} / \mathrm{g})$ at $25^{\circ} \mathrm{C}$ & $0 \cdot 207$ & $0 \cdot 122$ \\
Tensile strength $(\mathrm{MPa})$ & 11.4 & - \\
Hardness $(\mathrm{HB})$ & $30-58$ & $7 \cdot 0$ \\
Elastic modulus in tension $(\mathrm{GPa})$ & $77 \cdot 59$ & 32 \\
\hline
\end{tabular}

$d_{50}$ and $d_{99}$ values for the treated powders as compared to the control powders. The $d_{50}$, in general, in bismuth powders exhibited an increase while $d_{99}$ did not show a clear trend in the treated powders as compared to the control powders. The decrease in the particle sizes of the antimony powders (as in the case of $d_{50}$ and $d_{99}$ ) could be due to fracturing of the powders or the rounding of the particles while in the case of bismuth the increase (as in the case of $d_{50}$ ) could be due to elongation or welding of the particles. This is analogous to the fracturing and welding of powders during the mechanical milling/alloying process during which the fracturing or welding of the powder particles depend on the ductility/brittleness of the powders.

The percent change in particle sizes $\left(d_{50}\right.$ and $\left.d_{99}\right)$ of various treated powders with respect to control powders are shown in figures $1(\mathrm{a})-(\mathrm{b}) . d_{50}$ (figure $1(\mathrm{a})$ ) in all the treated powders of antimony exhibited a decrease while three out of four treated powders of bismuth exhibited an increase in percent change in particle size. $d_{99}$ (figure 1(b)) in all the treated powders of antimony exhibited a decrease while in the case of bismuth two out of four treated powders exhibited a decrease. This indicates that the external energy causes a decrease in the particle size of the antimony powders while in the case of bismuth powders the results are unclear. From table 2 it can be noticed that bismuth has much lower hardness and modulus of elasticity. Therefore, under the influence of an external force it will have a tendency to elongate in size. Fracture can only occur at defects or due to work hardening. Either way the results indicate that the non contact energy used influences the powders at the grain/ crystallite level causing deformation/fracture/welding of the particles.

\subsection{Specific surface area}

Table 3 shows the BET surface area values of the control and treated powders. Figure 2 shows the percent change in the BET surface area of the treated powders of both 
Table 3. BET surface area of control and treated powders

\begin{tabular}{lccccc}
\hline & \multicolumn{2}{c}{ BET surface area $\left(\mathrm{m}^{2} / \mathrm{g}\right)$} & & \multicolumn{2}{c}{ Percent change in BET surface area } \\
\cline { 2 - 3 } \cline { 5 - 6 } Treatment & Antimony & Bismuth & & Antimony & Bismuth \\
\hline Control & 0.24 & 0.05 & & & -27.89 \\
Treated $T 1$ & 0.21 & 0.03 & & -14.08 & -23.21 \\
Treated $T 2$ & 0.18 & & & -8.33 & \\
Treated $T 3$ & 0.26 & & & & \\
\hline
\end{tabular}

Table 4. Crystallite size of control and treated powders.

\begin{tabular}{lccccr}
\hline & \multicolumn{2}{c}{ Crystallite size ' $\mathrm{G}$ ' $\times 10^{-9} \mathrm{~m}$} & & \multicolumn{2}{c}{ Percent change in crystallite size } \\
\cline { 2 - 3 } \cline { 5 - 6 } Treatment & Antimony & Bismuth & & Antimony & Bismuth \\
\hline Control & 61.00 & 85.11 & & & \\
Treated $T 1$ & 60.99 & 141.83 & & 0.00 & 66.65 \\
Treated $T 2$ & 106.74 & 85.11 & & 74.99 & 0.00 \\
Treated $T 3$ & 71.15 & 70.92 & & 16.65 & -16.67 \\
Treated $T 4$ & 71.16 & 60.77 & & 16.66 & -28.60 \\
\hline
\end{tabular}

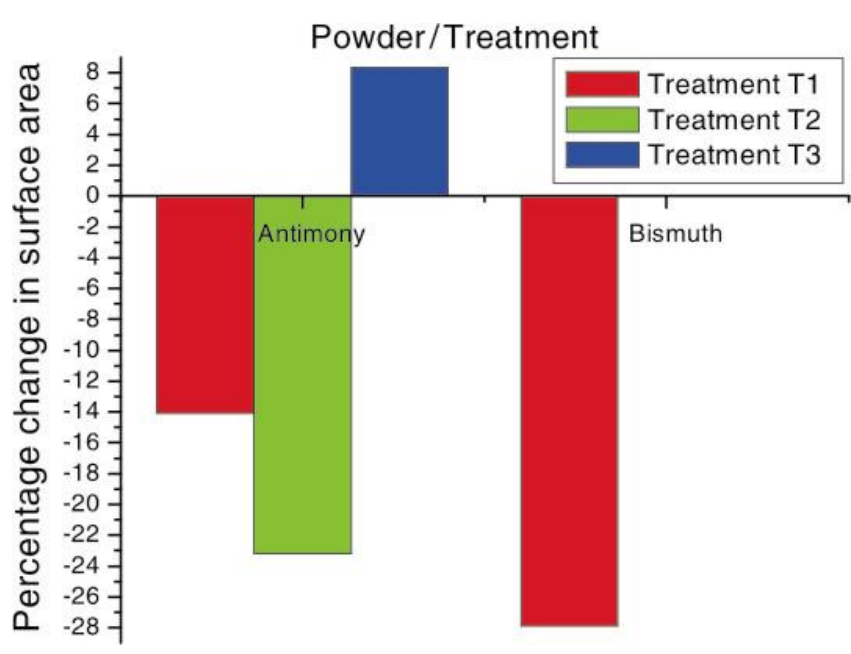

Figure 2. Percentage change in BET surface area in treated powders.

antimony and bismuth. The percent change in surface area values show a similar trend as that of the surface area value and indicate the extent up to which the surface area has changed due to the treatment. Except for one sample the surface area decreased on treatment in both the powders. This result is contrary to the observed decrease in particle size. Possibly the fresh surfaces of the particles obtained after fracture got oxidized. This is also confirmed by the charging of particle surfaces as observed in SEM studies (figures 7 and 8) described in $\$ 3.7$. In order to find the cause for the change in particle size the powders have been examined by X-ray diffraction.

\subsection{Crystallite size}

The crystallite size of the control and treated powders and the percent change after treatment as obtained from the
X-ray peak broadening are shown in table 4 , while the percent change is shown in figure 3 . The crystallite size had changed substantially showing both increase as well as decrease, indicating heavy plastic deformation. The latter is not possible as the crystal structure remained the same. The existence of severe lattice strain is evidenced by the change in lattice parameters. It is possible that these internal strains made dislocations to move on the slip planes and intersecting slip planes built in stress concentrations to such an extent causing the crystal to fracture at the sub boundaries. This is perhaps the explanation for decrease in crystallite size. On the other hand, when the dislocations move unhindered, they might reorient the planes on either side of the crystallite boundaries resulting in an increased crystallite size. In case of antimony powders the crystallite size values as well as the percent change in crystallite size values were in general found to increase due to the treatment. In the case of bismuth powders the crystallite size values as well as the percent change in crystallite size values were in general found to decrease due to the treatment. It is clear that the external energy, even without physical contact had an impact at the grain/crystallite level of the powders.

\subsection{Volume of unit cell}

From the lattice constants, the volume of the unit cells of antimony and bismuth were calculated for the control as well as the treated powders (table 5). From the volume of the unit cells the percent change in the volume of the unit cell of the treated powders (with respect to the control powders) were calculated and are shown in figure 4 . In the case of antimony the treated powders exhibited an increase in the percent change in the volume of the unit cell for all the treated powders implying that the unit cell 
Table 5. Volume of the unit cell, charge and atomic weight for control and treated powders.

\begin{tabular}{|c|c|c|c|c|c|}
\hline \multirow[b]{2}{*}{ Characteristic } & \multirow[b]{2}{*}{ Treatment } & \multicolumn{2}{|c|}{ Magnitude of characteristic } & \multicolumn{2}{|c|}{ Percent change in characteristic } \\
\hline & & Antimony & Bismuth & Antimony & Bismuth \\
\hline Volume of unit cell $\left(\mathrm{cm}^{3}\right)$ & $\begin{array}{l}\text { Control } \\
\text { Treated } T 1 \\
\text { Treated } T 2 \\
\text { Treated } T 3 \\
\text { Treated } T 4\end{array}$ & $\begin{array}{l}1.8109 \times 10^{-22} \\
1.8115 \times 10^{-22} \\
1.8119 \times 10^{-22} \\
1.8136 \times 10^{-22} \\
1.8115 \times 10^{-22}\end{array}$ & $\begin{array}{l}2 \cdot 1257 \times 10^{-22} \\
2 \cdot 1239 \times 10^{-22} \\
2 \cdot 1244 \times 10^{-22} \\
2 \cdot 1295 \times 10^{-22} \\
2 \cdot 1397 \times 10^{-22}\end{array}$ & $\begin{array}{l}0 \cdot 03 \\
0 \cdot 05 \\
0 \cdot 15 \\
0 \cdot 04\end{array}$ & $\begin{array}{r}-0.09 \\
-0.06 \\
0.18 \\
0.66\end{array}$ \\
\hline $\begin{array}{l}\text { Effective nuclear charge per unit } \\
\left.\text { volume of the atom (coulombs } / \mathrm{cm}^{3}\right)\end{array}$ & $\begin{array}{l}\text { Control } \\
\text { Treated } T 1 \\
\text { Treated } T 2 \\
\text { Treated } T 3 \\
\text { Treated } T 4\end{array}$ & $\begin{array}{l}1.950 \times 10^{5} \\
1.949 \times 10^{5} \\
1.948 \times 10^{5} \\
1.946 \times 10^{5} \\
1.949 \times 10^{5}\end{array}$ & $\begin{array}{l}2 \cdot 708 \times 10^{5} \\
2 \cdot 712 \times 10^{5} \\
2 \cdot 711 \times 10^{5} \\
2 \cdot 701 \times 10^{5} \\
2 \cdot 682 \times 10^{5}\end{array}$ & $\begin{array}{l}-0.050 \\
-0.081 \\
-0.226 \\
-0.053\end{array}$ & $\begin{array}{r}0.128 \\
0.092 \\
-0.264 \\
-0.981\end{array}$ \\
\hline Atomic weight (grams/gram atom) & $\begin{array}{l}\text { Control } \\
\text { Treated } T 1 \\
\text { Treated T2 } \\
\text { Treated T3 } \\
\text { Treated } T 4\end{array}$ & $\begin{array}{l}123 \cdot 06 \\
123 \cdot 10 \\
123 \cdot 12 \\
123 \cdot 24 \\
123 \cdot 10\end{array}$ & $\begin{array}{l}210 \cdot 81 \\
210 \cdot 63 \\
210 \cdot 68 \\
211 \cdot 19 \\
212 \cdot 20\end{array}$ & $\begin{array}{l}0 \cdot 03 \\
0.05 \\
0 \cdot 15 \\
0 \cdot 04\end{array}$ & $\begin{array}{r}-0.09 \\
-0.06 \\
0.18 \\
0.66\end{array}$ \\
\hline
\end{tabular}

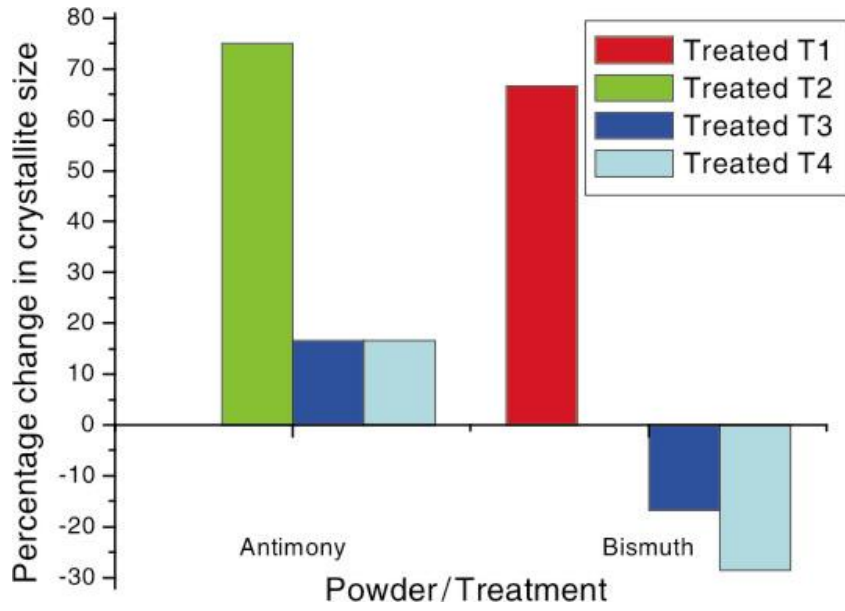

Figure 3. Percentage change in crystallite size in treated powders.

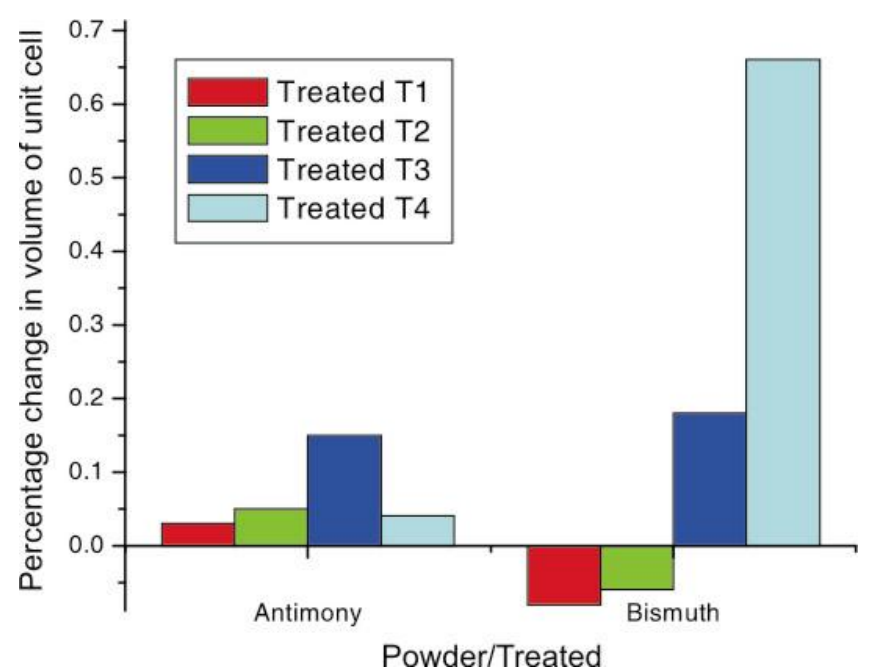

Figure 4. Percentage change in volume of unit cell of treated powders.

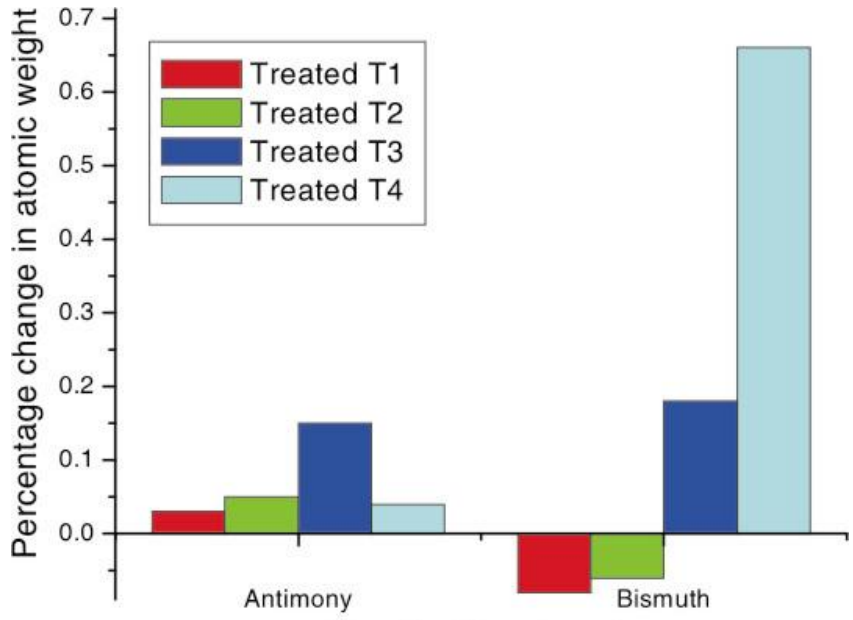

Powder/Treatment

Figure 5. Percentage change in atomic weight of treated powders.

expanded due to the influence of the energy. The bismuth powders on the other hand exhibited a slight decrease in the percent change in the volume of the unit cell for two treated powders while in the case of the other two treated powders they exhibited a significant increase.

The atomic size in a bound state is not constant and varies depending on the environment of nearest neighbours. The lattice parameters are decided by the equilibrium inter atomic distance where the attractive forces due to nuclear charges are balanced by the repulsive forces due to the orbiting electrons. An increasing distance from the nucleus decreases the effect of nuclear charge on the outer electrons. When atoms are subjected to an external compressive force the rather flexible electron cloud is likely to be pushed closer to the central nucleus thereby decreasing the volume of the atom and 
Table 6. SDTA of bismuth powder.

\begin{tabular}{|c|c|c|c|c|c|c|c|}
\hline Element & Treatment & $\begin{array}{c}\text { Mass of sample, } \\
m_{\mathrm{o}}(\mathrm{mg})\end{array}$ & $\begin{array}{l}\text { Latent heat of } \\
\text { fusion, } \Delta H(\mathrm{~J} / \mathrm{g})\end{array}$ & $\begin{array}{c}\text { Melting } \\
\text { point }\left({ }^{\circ} \mathrm{C}\right)\end{array}$ & $\begin{array}{l}\text { Mass of sample at } \\
\text { melting point }(\mathrm{mg})\end{array}$ & $\begin{array}{c}\text { Percent } \\
\text { change (mass) }\end{array}$ & $\begin{array}{l}\text { Percent change } \\
\qquad(\Delta H)\end{array}$ \\
\hline \multirow{5}{*}{ Bismuth } & Control & 34.73 & $45 \cdot 39$ & $273 \cdot 01$ & 34.77 & $0 \cdot 12$ & \\
\hline & Treated 1 & $30 \cdot 98$ & $42 \cdot 85$ & 272.07 & $30 \cdot 71$ & $-0 \cdot 87$ & $-5 \cdot 59$ \\
\hline & Treated 2 & $29 \cdot 92$ & 28.92 & 271.77 & 29.97 & $0 \cdot 15$ & $-36 \cdot 29$ \\
\hline & Treated 3 & $26 \cdot 67$ & $25 \cdot 05$ & $272 \cdot 16$ & $24 \cdot 00$ & -9.99 & $-44 \cdot 81$ \\
\hline & Treated 4 & $20 \cdot 89$ & 44.57 & $272 \cdot 51$ & $20 \cdot 97$ & $0 \cdot 38$ & $-1 \cdot 80$ \\
\hline
\end{tabular}

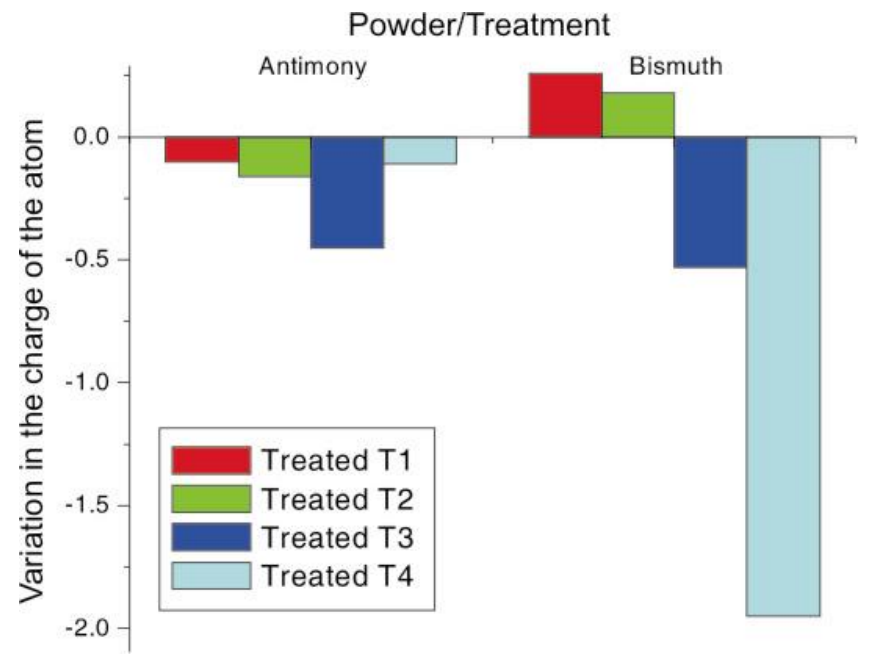

Figure 6. Variation in charge of the atom in treated powders

increasing the effective nuclear charge. The reverse might happen when the external force is tensile. The atoms are likely to be pulled apart thereby increasing the volume and decreasing the effective nuclear charge. Thus the density should increase during compression and decrease during tension. The reverse happens in the case of unit cell volume. The observed results are in agreement with the changes in crystallite size. Perhaps the cumulative changes in the volume of unit cells had caused changes in crystallite size which in turn caused changes in particle size.

\subsection{Atomic weight and charge of atoms}

Figure 5 shows the percent change in the atomic weight for the treated powders of both antimony and bismuth. The percent change in the atomic weight for the treated powders of antimony was positive and higher as compared to the control samples. In the case of bismuth powders, for two of the treated powders it was positive and higher while for the other two it was negative and lower. Figure 6 shows variation in the charge of the atoms for both the powders. The charge of the atoms in the case of antimony was found to decrease in the treated powders. In the case of bismuth for some treated samples the charge was found to decrease while for others it was found to increase. An interesting aspect of the present experimental results is that the normalized parameters computed for various characteristics showed a direct or inverse proportionality to the percent change in volume of unit cell.

A decrease in lattice parameter ' $a$ ' and unit cell volume will increase the density. This in turn should decrease the size of the atom by compressing electron cloud closer to the nucleus. The effective nuclear charge on the surface of the atom therefore increases as has been observed in the present experiments. The observed decrease in atomic weight and hence the sum of protons and neutrons in the nucleus with increase in density or decrease in lattice parameter is unusual.

\subsection{Thermal analysis}

Change in thermal characteristics of treated antimony powder in nitrogen atmosphere was studied using DSCTGA. While there was no significant change in melting point, the latent heat of fusion had decreased by $11.47 \%$ (changed from $-163 \cdot 17$ to $144.45 \mathrm{~J} / \mathrm{g}$ ). The mass of the sample had decreased by $9 \cdot 72 \%$ indicating loss due to vapourization. The experiments carried out using DTADTG indicated that the temperature corresponding to maximum rate of decrease in mass was decreased by $6.51 \%$ (changed from $601 \cdot 11$ to $561.98^{\circ} \mathrm{C}$ ). The decrease in latent heat of fusion without significant change in melting temperature suggests that the powders are already in a high energy state prior to melting.

Simultaneous differential thermal analysis (SDTA) was conducted on control and four different treated powders of bismuth. The results are shown in table 6. All the powders showed a decrease in latent heat of fusion, the maximum decrease being $44.81 \%$ (decrease from 45.39 to $25.05 \mathrm{~J} / \mathrm{g}$ ). There was no significant change in melting temperature. The decrease in latent heat of fusion without significant change in melting temperature once again suggests that the powders are already in a high energy state prior to melting.

\subsection{Scanning electron microscopy}

Figure 7 shows SEM micrographs of the control as well as treated powders of antimony while figure 8 shows 

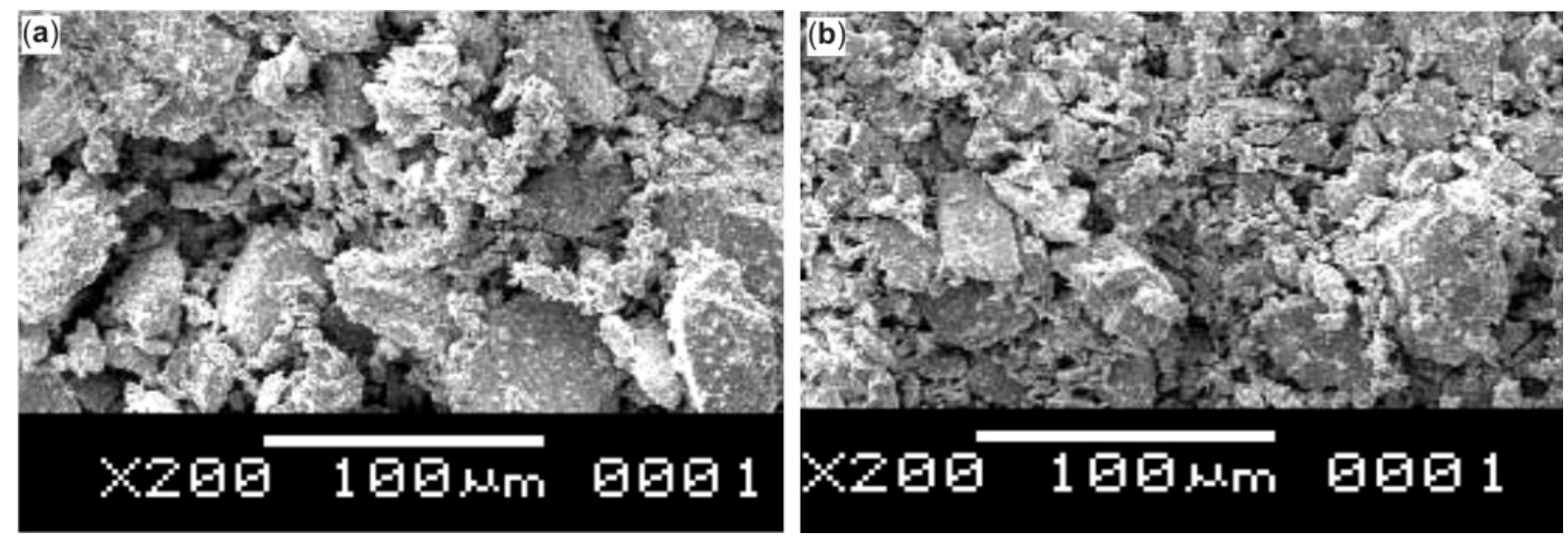

Figure 7. SEM micrographs of (a) control and (b) treated antimony powders.
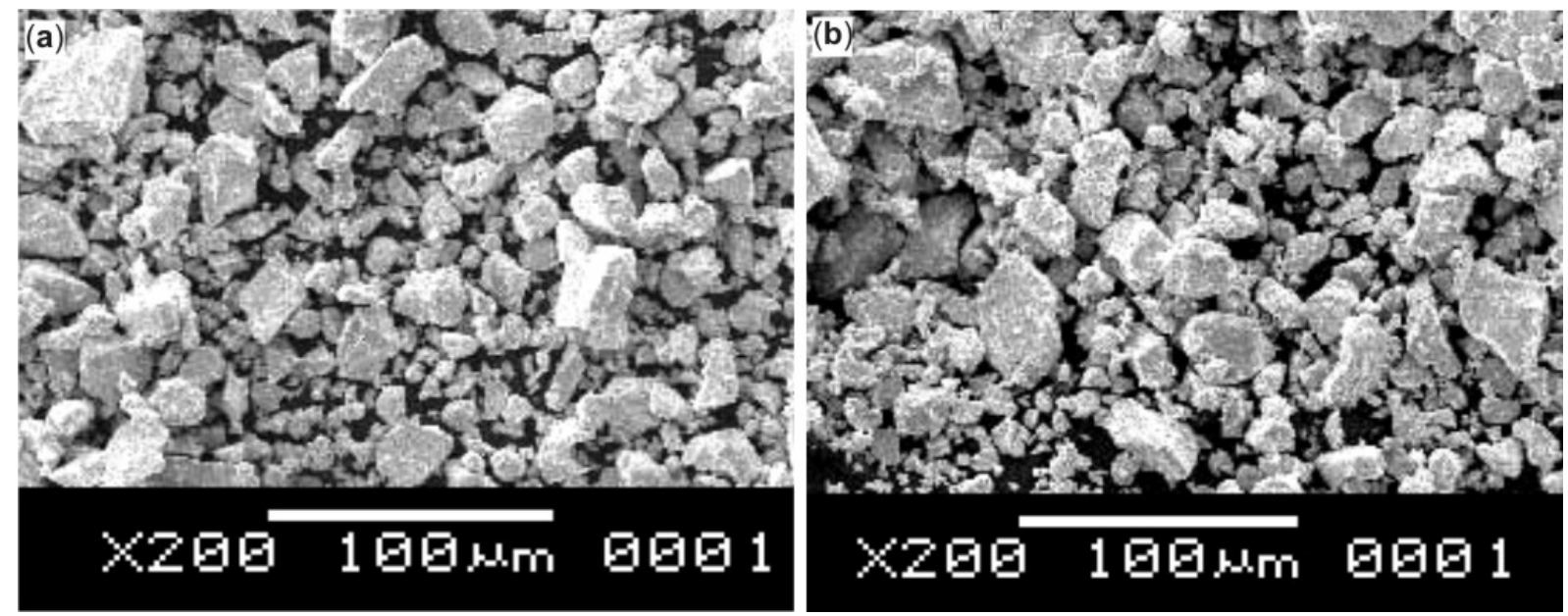

Figure 8. SEM micrographs of (a) control and (b) treated powder of bismuth.

SEM micrographs of the control as well as the treated powders of bismuth. The morphology of the control powders of antimony was flaky and geometrical, and it appeared to be milled. After treatment the particle size was reduced and the morphology although was flaky was less geometrical. Fracture seems to have taken place due to the treatment at the inter particle boundaries. The morphology of the bismuth control powders was irregular and the powders were agglomerated. On treatment the powders appeared to increase in the particle/agglomerate size and the morphology was more irregular in nature. In both the cases the surface of the powders appears to be charged possibly due to oxidation of freshly fractured surfaces.

\section{Conclusions}

(I) The non contact external energy caused a change in the particle size, surface area and crystallite size of the antimony and bismuth metal powders.
(II) The treated powders of antimony and bismuth exhibited an increase as well as a decrease in volume of unit cell, effective nuclear charge per unit volume of the atom and the atomic weight.

(III) SEM examination of the treated powders exhibited a change in particle morphology and particle/agglomerate size.

(IV) Thermal analysis of the treated powders showed a decrease in latent heat of fusion thereby indicating the treated powders to be in a high energy state.

\section{Acknowledgements}

We thank Dr Shrikant Patil, Mr Harish Shettigar, Mrs Subba Lakshmi M Tallpragada and Ms Archana Bulbule, Society for Divine Life, for their active help, and the staff of various laboratories for conducting various characterization experiments. We thank Dr Cheng Dong, NLSC, Institute of Physics, and Chinese Academy of Sciences 
for permitting us to use PowderX software for analyzing XRD results.

\section{References}

Amarchand S, Mohan T R R and Ramakrishnan P 2000 Ultrafine grained materials (eds) R S Mishra et al (Warrendale PA, USA: The Minerals, Metals and Materials Society (TMS)) pp 33-40

Benjamin J S 1976 Sci. Am. 23440

Dabhade V V, Mohan T R R and Ramakrishnan P 2001 Appl. Surf. Sci. 182390
Fecht H J 1996 Nanomaterials: synthesis, properties and applications (eds) A S Edelstein and R C Cammarota (Bristol: Institute of Physics Publishing) pp 89-92

Gleiter H 1992 Nanostructured Mater. 11

Mayo M J 1996 Int. Mater. Rev. 4185

Mohan T R R, Murty T S, Ramakrishnan P and Gutmanas E Y 1999 Advances in powder metallurgy and particulate materials (eds) C L Rose and M H Thibadeau (Metal Powder Industries Federation, APMI), pp 159-164

Suryanarayana C 1995 Int. Mater. Rev. 4041

Suryanarayana C 1999 Non-equilibrium processing of materials (ed.) C Suryanarayana (Oxford: Pergamon Materials Series) pp 66-67 